\title{
SPACE SYNTAX THEORY
}

\section{Understanding human movement, co-presence and encounters in relation to the spatial structure of workplaces}

\author{
Kerstin Sailer* and Petros Koutsolampros
}

\section{Background}

Space syntax as a theory aims to identify the link between spatial configuration and human behaviour, and, more specifically, examine how different parameters of the built environment affect different sets of behaviours such as movement and unplanned encounters. At its core, space syntax primarily employs spatial networks allowing for the study of local effects such as co-visibility and co-presence, but also building-wide effects, such as its overall level of depth and the overall distance to the entrance and other facilities.

\subsection{An interdisciplinary theory across spatial scales and settings}

The theory has its roots in the study of settlements and houses, where it was developed as a way to formalise spatial ordering principles by measuring the geometric properties of space and thus allowing for comparison to social behaviour. Essentially, the theory proposes to understand space in its own right - neither as a flowing entity, nor as the leftover between buildings or walls - but as a system of parts (e.g. rooms, corridors) and their interconnections (e.g. doors, staircases, elevators). Inspired by mathematics and linguistics (hence the term 'syntax' alluding to how elements can be joined together and combined in different ways by rules), the theory was pioneered in the 1970s at University College London, UK, by Bill Hillier, Julienne Hanson and colleagues. The theoretical base was first articulated in a 1976 paper simply called 'Space Syntax' (Hillier, Leaman, Stansall, \& Bedford, 1976) and more fully in The Social Logic of Space by Hillier and Hanson (1984), along with an initial set of methods and techniques to capture both spatial configuration and human behaviour.

It is worth noting that from the beginning space syntax worked across the scales. Early examples in Hillier and Hanson (1984) included small settlements and villages, but also simple houses, palaces and even temporary accommodations such as the Mongolian yurt, elaborating how spatial principles of access and separation of spaces by social spheres (e.g. between males and females, visitors and inhabitants) constituted a system of presence and encounters.

Since its origins, space syntax has grown into a worldwide community of researchers, practitioners and consultants studying a wide spectrum of phenomena. Applications include

*Corresponding author: k.sailer@ucl.ac.uk 
architecture (Peponis, Bafna, Dahabreh, \& Dogan, 2015) and urban planning (Karimi, 2012), but also embrace truly interdisciplinary contributions to fields as diverse as archaeology (Dawson, 2002), history (Griffiths, 2012), sociology (Liebst \& Griffiths, 2019), management (Thomas, 2019), neuroscience (Javadi et al., 2016) and biology (Varoudis, Swenson, Kirkton, \& Waters, 2018), to name a few.

Due to its prolific output and significant contribution to our understanding of the inner workings of cities, space syntax is sometimes mistaken as an urban theory, yet this is far from true. While The Social Logic of Space mainly focused on the analysis of simple settlements and houses, the relevance of the theory for the study of offices and other complex building types such as museums, hospitals, schools and so on was already manifest. For example, Hillier and Hanson (1984) reflected on the move of an organisation from cellular space to open plan, which was described as a move from status differences and power (cellular) to synchronicity and control (open plan). The first full implementation of space syntax in workplace settings was published by Hillier and Grajewski (1990), where a set of seven offices from the UK, the US and Scandinavia were examined. This lay the foundation for a rich research programme on office layouts and space syntax, with universities in the UK, the US and Sweden being at the heart of research efforts to understand the relationship between workplace design parameters and organisational outputs such as chance encounters, collaboration and productivity.

\subsection{Assumptions and representations common to space syntax theory}

Before focusing on workplace applications and findings in the next section, it is useful to understand more about the way space syntax represents and measures spatial qualities. Workplace examples will be used throughout to illustrate the space syntax approach.

The core assumption of the theory is that space is meaningful in the way different parts are linked to form an interconnected spatial system that humans inhabit and move through. By treating space as a complex network of interconnected parts (such as rooms and corridors), the approach allows for measuring how important (or central) a room or corridor is in a whole system, such as a building. The theory then predicts how frequently different parts of a space will be used depending on how central the space is in the overall network: highly integrated spaces will be used more intensively, while more segregated spaces will be quieter by nature. Space usage patterns are typically observed in space syntax research through direct observation methods in order to test and verify the predictive power of the theory (see details in Section 3 below).

Therefore, space as an infinite flowing entity needs to be cut into distinct 'chunks' for the theory to be applicable. Various representations have been suggested over the years, such as axial and segment line maps pronouncing the linear quality of human movement and spatial experience; convex maps which partition space into two-dimensional convex elements (where each point is intervisible with all others), expressing the qualities of human co-presence; but also most recently, more complex and nuanced representations, such as visibility graphs which tessellate a space into grid cells and take human visual fields into account.

Two of these spatial representations have been primarily used for workplace studies, axial/segment models and visibility graph analysis (VGA, originally described by Turner, Doxa, O'Sullivan, \& Penn, 2001), both sharing a common base: a spatial network (see Figures 21.1a and 21.2a).

Axial and segment models are based on lines following potential movement paths through a space (as shown in Figure 21.1a). Wherever lines intersect, a connection is made between one space (line) and another. Segment models are more fine-grained, cutting off long lines, for instance in corridors, into shorter segments at each intersection. 
(a)

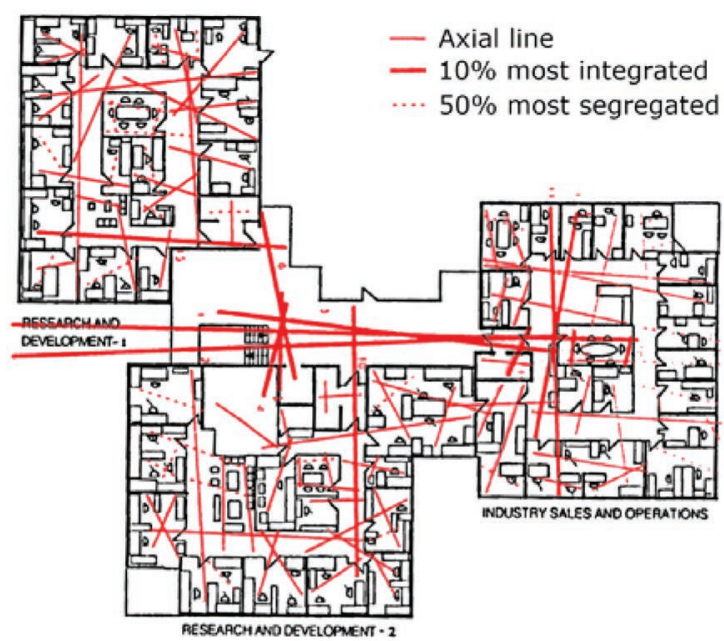

(b)

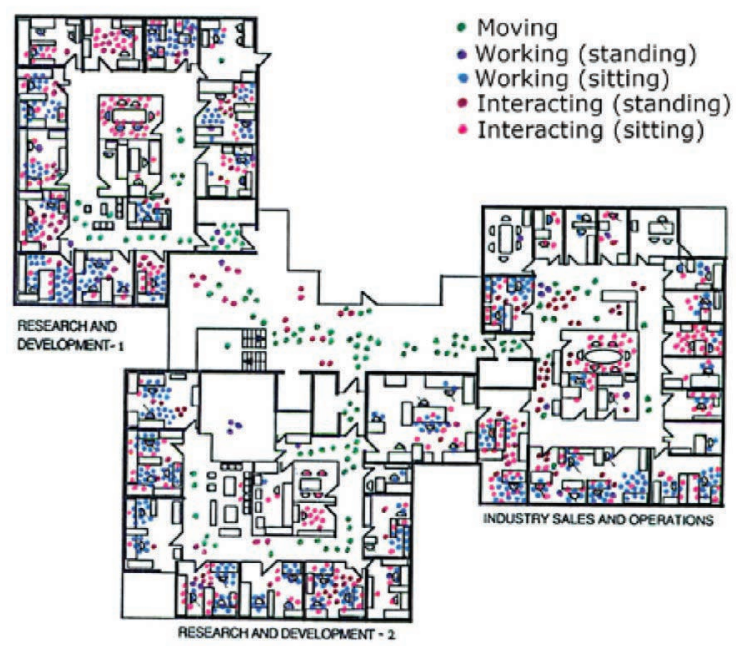

Figures 21.1 Axial map (a) and snapshot data (b) from Hillier and Grajewski (1990) and Grajewski (1992)

These resulting networks can then be described mathematically and quantitatively with the help of graph theory. The two main theoretical constructs used in space syntax are (1) connections and (2) depth. Connectivity is a local metric, for instance how many doors a room has or how many offices are accessible from one stretch of corridor. Depth, in contrast, is a form of distance metric. Step depth for example describes how many steps lie between one spatial element and another (such as from one cellular office to another via two corridors). Taken further, path lengths can be calculated from one point of interest (entrance) to another (desks), but also from any point to all other points, which gives a measure of the overall 'integration' of a spatial system. These constructs are comparable to degree and closeness centrality metrics used in other network-related disciplines.

The calculations employed in axial or segment maps can also be used in any other representation. The second commonly used workplace model, a VGA (as shown in Figure 21.2a) is based 
(a)

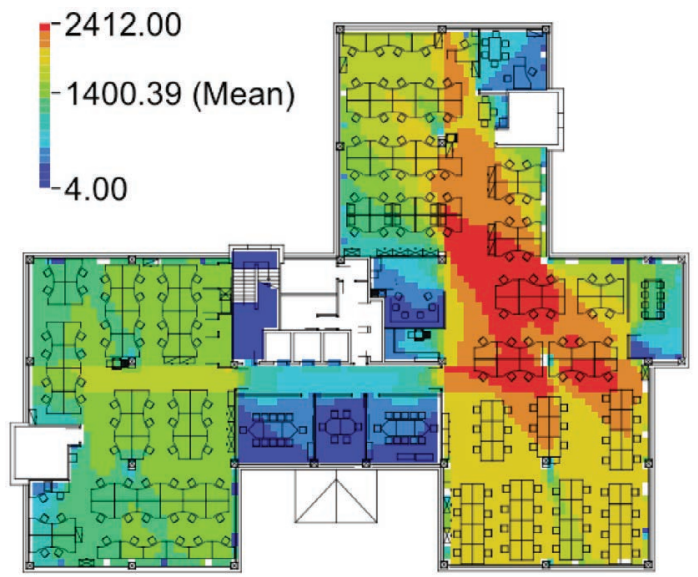

(b)

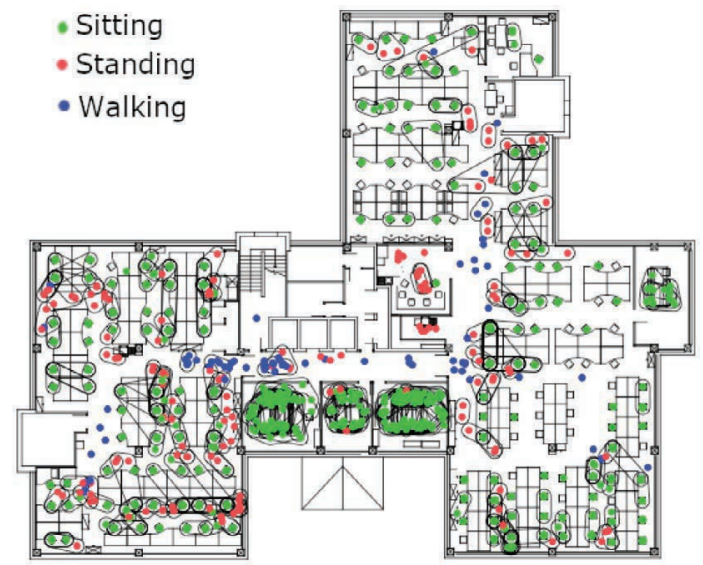

Figure 21.2 Connectivity in visibility graph analysis (a) and respective snapshot data (b)

on a regular grid superimposed on the plan, creating thousands of micro-locations, often called 'pixels', that represent a human potentially standing in that spot. From each pixel an isovist is created, described by Benedikt (1979) as the visible area on the plan from that vantage point. A visibility graph connects isovists and calculates, among a plethora of other parameters (Koutsolampros, Sailer, Varoudis, \& Haslem, 2019), visual integration (i.e. path length), which represents how often someone would have to 'look around the corner' from a given point to have seen all other spaces from there.

\section{Applicability to workplace studies}

The aim of most applications of space syntax theory in the workplace has been to explore how spatial configuration affects behaviours such as movement and encounters. To reach this aim, most studies identified the occurrence, frequency and location of different activities and brought this together with configurational properties of locations. By examining how spaces with different configurations attracted people to specific locations, the studies were able to suggest specific elements of design that might affect each behaviour. 
Following the core space syntax assumptions, the study by Hillier and Grajewski (1990) confirmed that more integrated parts of offices showed higher levels of both movement and interaction compared with more segregated places in offices. This showed that the basic assumptions of the theory applied well to buildings and particularly to workplaces as ways to highlight the locations of movement, occupancy and interaction.

\subsection{Workplace phenomena across scales}

In line with the origins of the theory, workplace studies developed different metrics to describe the qualities of a space within a network, alternating between micro-scales (for instance how space is experienced from one particular vantage point), meso-scales (how human experience unfolds between two points of interest) and macro-scales (how the location of a particular place in the overall spatial system contributes to its usage). These different scales could also be described on a range from egocentric analyses (depth from one place) to allocentric ones (from any place to all others).

Table 21.1 gives an overview of exemplary workplace research studies, showing the breadth of space syntax workplace research approaches. On a micro-scale, visibility from a particular point of interest was studied; the meso-scale covered patterns of inter-visibility of desks, or distance paths between all co-workers; while the macro-scale highlighted the centrality of a room or place in relation to the building as a whole.

An underlying shared principle of all these approaches is the search for a patterning, where spatial properties of a location, place or building as a whole can be used to explain the occurrence and prevalence of activities and human space usage behaviours. A spatial layout in this sense can be seen as a generator of a 'field of probabilistic encounter' (Hillier, Burdett, Peponis, \& Penn, 1987). This means that some spatial characteristics, such as the integration of a location, make it more likely for certain activities to occur, such as increased levels of encounter.

\subsection{Overview of workplace research findings on offices}

Building on initial findings, workplace studies in space syntax established the relationship between configuration and behaviours, highlighting how more integrated spaces and buildings

Table 21.1 Exemplary workplace research studies across scales using space syntax

\begin{tabular}{|c|c|c|}
\hline & Constructs & Study \\
\hline \multirow[t]{2}{*}{ Micro-scale } & Visibility from a point of interest & $\begin{array}{l}\text { Alavi, Verma, Mlynar, and Lalanne } \\
\text { (2018) }\end{array}$ \\
\hline & Local visibility while walking & Backhouse and Drew (1992) \\
\hline \multirow[t]{3}{*}{ Meso-scale } & $\begin{array}{l}\text { Patterns of visibility between } \\
\text { desks }\end{array}$ & Beck (2015) \\
\hline & Distances between co-workers & $\begin{array}{l}\text { Sailer and McCulloh (2012), } \\
\text { Wineman, Hwang, Kabo, } \\
\text { Owen-Smith, and Davis (2014) }\end{array}$ \\
\hline & Paths from desks to facilities & $\begin{array}{l}\text { Sailer (2007), Owen-Smith, } \\
\text { Kabo, Levenstein, Price, } \\
\text { and Davis (2012) }\end{array}$ \\
\hline Macro-scale & Centrality of a particular place & $\begin{array}{c}\text { Hillier and Grajewski (1990), Penn, } \\
\text { Desyllas, and Vaughan (1999) }\end{array}$ \\
\hline
\end{tabular}


accounted for higher densities of movement and interaction. It was shown, for example, that office workers in more integrated workspaces showed higher degrees of satisfaction with interaction support as well as a higher sense of community (Wineman \& Adhya, 2007). Research also established, however, that a large degree of variation in activities such as interaction was due to functional allocations and was predominantly found next to workstations (Rashid, Kampschroer, Wineman, \& Zimring, 2006; Steen, Blombergsson, \& Wiklander, 2005), regardless of their position or spatial characteristics such as integration.

Further studies underlined the importance of configurational aspects of workplaces for innovation by showing how the spatial configuration of integrated workplaces generated random contacts and unplanned encounters required for innovation (Penn et al., 1999). The relationship between spatial integration and generativity, that is, the ability to create new ideas and relationships in workplaces, was confirmed using a larger sample of office buildings (Sailer, Pomeroy, Raheem, Budgen, \& Lonsdale, 2012). This was built upon in a more recent study arguing that not just integrated layouts but also the distribution of teams made a difference to the innovative capacity of organisations by bringing diverse sets of people together in day-to-day work (Sailer \& Thomas, 2019). While the previous studies used qualitative evidence to infer innovation, more explicit and quantitative links to innovation were made in a few studies bringing together workplace layout, random encounters and innovative outputs such as patents and publications of scientists (Penn et al., 1999; Toker \& Gray, 2008; Wineman et al., 2014).

A similar argument was made for the supportive role of an integrated and easily readable workplace layout, which was shown to relate to interaction networks, but also to organisational productivity and knowledge work using billable hours as a proxy (Peponis et al., 2007). Studies focusing on corporate real estate also pointed out that there is potential for the measurements provided by space syntax to act as measurements for organisational performance (Appel-Meulenbroek \& Feijts, 2007).

Finally, studies also explored the relationship between spatial layouts and perceptions of privacy. While one study found no relations (Wineman \& Adhya, 2007), another reported that workers in larger open, more integrated areas tended to find concentration more difficult (Hong \& Yoo, 2010). The relationship between openness and privacy was also shown in studies in the micro-scale (Alavi et al., 2018), where the visual fields of specific staff members were found to relate to seat preference (staff preferred less-exposed seats), especially in rooms designated for quiet work.

In addition to exploring more complex behavioural constructs, eventually researchers started incorporating other aspects of workspace beyond pure geometric configuration such as attractors (Sailer, 2007; Owen-Smith et al., 2012) and organisational cultures (Peponis, 1985). The effect of attractors has in fact been shown to be non-negligible, especially in understanding movement, and in some cases a more important parameter than integration (Sailer, 2007). For interaction and chance encounter, however, the simulation of actual paths to attractors was found to be a highly effective predictor (Kabo, Hwang, Levenstein, \& Owen-Smith, 2015; Owen-Smith et al., 2012). It was specifically shown that if the paths of researchers in two university buildings had common zones, there was a higher likelihood that those scientists would collaborate as co-authors in publications and grant applications.

\subsection{Overview of workplace research findings in other settings}

Due to its wide range of applications, space syntax has contributed to our understanding of different settings other than traditional, corporate offices, since those can be considered workplaces, too.

Early studies in the space syntax domain explored laboratory buildings (Hillier \& Penn, 1991; Serrato \& Wineman, 1999; Wineman \& Serrato, 1997), arguing that proximity and integration 
afforded scientific knowledge creation. The spatial culture of factories arguably also touches upon work processes (Peponis, 1985). Work processes in hospitals such as communication patterns between caregivers in wards have long been studied using space syntax methods as well, showing how visibility in corridors enhanced professional communication (Pachilova \& Sailer, 2020) and how the workflow patterns of doctors and nurses differed according to visibility cues (Lu \& Zimring, 2012). Types of buildings with more diverse and complex workflow patterns such as universities have also been examined (Major et al., 2019) with promising but not strongly predictive results yet. Even studies in primary schools could be seen as workplace studies, for instance highlighting how high levels of integration in classrooms made it more difficult for teachers to adapt their teaching styles (Kishimoto \& Taguchi, 2014).

\section{Methodology/research approach}

Space syntax researchers typically analyse spatial structures in relation to human activities, hence this section clarifies methodological considerations for each of those aspects, but also how to bring them together.

\subsection{Spatial structure}

Detailed floor plans are an essential data source when studying workplaces following a space syntax approach. Axial or segment models require a researcher to draw lines of movement (for example in a CAD program or in a GIS system). A VGA requires a cleaned-up dxf file (with separate layers for walls, partitions, furniture, glass, etc.). These drawings are then imported into specialised open source software, such as depthmapX (depthmapX development team, 2019) to run the calculations. A manual by Al-Sayed, Turner, Hillier, Iida, and Penn (2014) can give details. An alternative software specifically for isovist and visibility analysis is called isovist (McElhinney, 2020), which reads dxf and svg file formats of plans.

The aforementioned apps create both visualisations and calculate the underlying metrics, which can be exported as csv files for further statistical analysis. A workflow in $\mathrm{R}$ has recently been developed (Koutsolampros \& Kostourou, 2019).

\subsection{Human activity}

For examining the locations of human behaviour, most studies employed either direct observations of where people perform various activities (so-called snapshots, as described by Vaughan, 2001) or questionnaires asking staff about their working practices and experiences of a workspace. Questionnaires in this tradition often involve asking staff about satisfaction with the workplace, their usage of facilities, but also their relationships to colleagues (e.g. who knows whom, who talks to whom). In some cases, this relational information was developed into a full analysis of the social network relations of staff, allowing for delving deeper into how spatial layouts afford human connections (Sailer \& McCulloh, 2012). Social network analysis was also applied to co-authorship networks in academic workplaces, linking collaborative work practices to the underlying campus building layout (Wineman, Kabo, \& Davis, 2009).

\subsection{Bringing space and usage together}

With space syntax being a quantitative method, human behaviour needs to be captured in quantifiable ways in order to overlap the two. While early studies in the 1980s relied on paperdrawn maps and hand-counted methods, most commonly today researchers import both syntax 
maps and human activity data as locational maps into a GIS system, such as QGIS, in order to perform spatial queries (for example how many people use a certain space and which syntactical qualities that same space has). In detail, in cases where axial lines were used (Hillier \& Grajewski, 1990) the locations of human behaviour were converted to counts on each individual line based on distance (i.e. how many people moving were close to each line), while in cases where VGA was used the researchers either counted the number of observations in each cell (Dell, 2012) or retrieved the spatial configuration parameters at the location of each observation (AppelMeulenbroek, 2009). For the actual comparison and to understand whether the relationship was significant, most studies relied on simple statistical models such as Pearson correlation, where the spatial configuration parameters (integration, connectivity etc.) were treated as independent variables and the human behaviour parameters (numbers of people moving/interacting, questionnaire responses) as dependent variables. Where human behaviour was measured as responses to questionnaires or properties of a social network, the comparison unit (i.e. the unit of analysis) chosen was typically a person or a pair of people, instead of a line or a grid cell. In these cases, the statistical models would compare the spatial configuration properties of the location of that person or pair (location integration or pair distance) against the questionnaire responses or social network properties.

\subsection{Future research possibilities}

Space syntax can look back to a history of almost half a century of research efforts, yet compared to more established sciences it can still be considered a young and emerging field. Specifically, in the field of workplace research, there are plenty of open questions to be answered.

Recent developments in the broader space syntax domain have been to diversify user groups and consider the ways in which one building or space may affect different demographics in a variety of ways based on their personal preferences, skills or individualities (Carlson, Hölscher, Shipley, \& Conroy Dalton, 2010; Griffiths \& Netto, 2015; Sailer, 2015). In the context of workplaces this could include a new focus on visitor and staff experiences, for example.

Since space syntax research on workplace layouts has only just begun to reach out to social network analysis, organisational theory, industrial sociology, environmental psychology and other such neighbouring fields, inter- and transdisciplinary approaches provide interesting opportunities (see for example Sailer \& Thomas, 2020b).

Further research possibilities lie in exploiting computational power and the existence of larger data sets to explore the emergence of generic patterns, as for example highlighted by recent papers comparing decision-making speed across 72 workplaces (Sailer \& Thomas, 2020a) and the study of travel concentration across 216 floors (Koutsolampros, Sailer, \& Haslem, 2020).

\section{Limitations}

There are a few limitations for the applicability of space syntax to workplace studies. Firstly, the hypothesis of central places attracting the majority of human usage frequency assumes that origins and destinations of movements are randomly distributed. While that is the case for large urban systems or in building types based predominantly on exploratory behaviour such as museums, workplaces could be described as targeted movement systems (from entrance to desk, from desk to meeting room/kitchen and so on). This resulted in partially contradictory findings across early studies but was addressed by later work taking attractor-based movement into account (Sailer, 2007). 
With its foundation in the analysis of plans, the third dimension is only slowly addressed (Conroy Dalton \& Dalton, 2015; Varoudis \& Psarra, 2014), and arguably that matters in workplaces, for instance in foyers or atria.

The biggest challenge for the field in general, however, is replicability and consistency of results. Various researchers (Kegel, 2018; Sailer, 2010) highlighted that extant research examined small samples, mostly of up to three cases with only few exceptions studying up to 10 cases. Additionally, studies employed vastly differing techniques and metrics at times but also proceeded with varying rigour. As a result, contradictory findings emerged, for instance on the relationship between movement and spatial integration, which was not consistently shown (Sailer, 2007). Thus, while the theory has been applied successfully, that is, to connect specific behaviours to certain elements of spatial configuration for some cases, establishing generalisable findings valid for large samples of workplaces is still underway (Koutsolampros, 2021).

\section{Theory relevance to practice}

The techniques and methods within the space syntax domain can play an important role for evidence-based design, which is defined as the conscientious and explicit use of current best evidence in taking decisions (Sailer, Budgen, Lonsdale, Turner, \& Penn, 2008). Over the last decades, this approach of an evidence-based practice originating from medicine has become popular in a variety of professional contexts, among them management, HR and design. The majority of evidence-based design applications lie in healthcare design (Ulrich, Quan, Zimring, Joseph, \& Choudhary, 2004; Ulrich et al., 2008), however with a relative scarcity of approaches in workplace design. The need for an evidence-based design practice is underlined by a survey of 420 practitioners in which $80 \%$ reported a desire to use evidence in their work, yet only $5 \%$ of practitioners collected some kind of data themselves (EBD Journal, 2015).

Space syntax theories can be incorporated in an evidence-based design practice in two different ways: firstly, to support the design process for new workplaces, and secondly, to examine the potentials and limitations of existing office spaces.

As part of the design process, the methods allow for measuring how integrated and connected a suggested office floor plan is, and thus highlighting desirable solutions among a series of options and enabling a systematic comparison of alternative layouts. For example, a case study of a radio station design in Ireland highlighted the integrative benefits of a large central staircase (Sailer, Budgen, Lonsdale, Turner, \& Penn, 2007). This way, designs may be iterated upon using evidence on their potential effectiveness in affecting office activities such as movement and interaction. The final designs may then adhere to specific targets, such as balancing the need for serendipitous interaction (i.e. for the dissemination of new ideas) and the requirement for quiet spaces to facilitate concentrated work, all the while retaining ease of movement through the building. Evidence created by use of space syntax tools also provides means to communicate and visualise the differences between design options to clients. Existing workplaces can also benefit from the application of the methods as evaluation tools to identify potential workflow bottlenecks, such as very central and important departments located at segregated spaces reducing the potential for collaboration. Examples for both applications are provided from the reflective practice of Spacelab architects in London (Sailer, Pomeroy, \& Haslem, 2015).

\section{Further reading}

- Al-Sayed, K., Turner, A., Hillier, B., Iida, S., \& Penn, A. (2014). Space syntax methodology. The Bartlett School of Architecture, UCL. 
- Hillier, B., \& Grajewski, T. R. (1990). The application of space syntax to work environments inside buildings: Second phase: Towards a predictive model. In Unit for architectural studies. London: The Bartlett School of Architecture and Planning, University College London.

- Hillier, B., \& Hanson, J. (1984). The social logic of space. Cambridge: Cambridge University Press (CUP).

- Koutsolampros, P., Sailer, K., Varoudis, T., \& Haslem, R. (2019). Dissecting visibility graph analysis: The metrics and their role in understanding workplace human behaviour. Paper presented at the 12th International Space Syntax Symposium. Beijing, China.

- Sailer, K. (2010). The space-organisation relationship. On the shape of the relationship between spatial configuration and collective organisational behaviours [Doctoral Dissertation]. Germany: TU Dresden.

\section{Acknowledgments}

Both authors contributed equally to writing this chapter.

\section{References}

Al-Sayed, K., Turner, A., Hillier, B., Iida, S., \& Penn, A. (2014). Space syntax methodology. Bartlett School of Architecture, UCL. Retrieved from http://discovery.ucl.ac.uk/1415080/

Alavi, H. S., Verma, H., Mlynar, J., \& Lalanne, D. (2018). The hide and seek of workspace: Towards human-centric sustainable architecture. In Proceedings of the 2018 CHI conference on human factors in computing systems (pp. 1-12). Montreal QC, Canada: Association for Computing Machinery. https://doi. org/10.1145/3173574.3173649

Appel-Meulenbroek, R. (2009). Knowledge sharing in research buildings and about their design. Proceedings of the 7 th international space syntax symposium. Retrieved from http://www.sss7.org/Proceedings/04\%20 Building\%20Morphology\%20and\%20Emergent\%20Performativity/004_AppelMeulenbroek.pdf

Appel-Meulenbroek, R., \& Feijts, B. (2007). CRE effects on organizational performance: Measurement tools for management. Journal of Corporate Real Estate, 9(4), 218-238.

Backhouse, A., \& Drew, P. (1992). The design implications of social interaction in a workplace setting. Environment and Planning B: Planning and Design, 19, 573-573.

Beck, M. P. (2015). Slicing the cake: An isovist-based analysis of computerised workplace configuration. Proceedings of the 10th international space syntax symposium. Presented at the 10th international space syntax symposium, London, UK. Retrieved from http://www.sss10.bartlett.ucl.ac.uk/wp-content/ uploads/2015/07/SSS10_Proceedings_014.pdf

Benedikt, M. L. (1979). To take hold of space: Isovists and isovist fields. Environment and Planning B: Planning and Design, 6(1), 47-65. https://doi.org/10.1068/b060047

Carlson, L. A., Hölscher, C., Shipley, T. F., \& Conroy Dalton, R. (2010). Getting lost in buildings. Current Directions in Psychological Science, 19(5), 284-289. https://doi.org/10.1177/0963721410383243

Conroy Dalton, R., \& Dalton, N. (2015). The problem of representation of 3D isovists. Paper presented at the 10th International Space Syntax Conference, London, UK.

Dawson, P. C. (2002). Space syntax analysis of Central Inuit snow houses. Journal of Anthropological Archaeology, 21(4), 464-480. https://doi.org/10.1016/s0278-4165(02)00009-0

Dell, T. L. (2012). The life of the lab: Creating collaborative workspaces for scientists [Doctoral dissertation]. University of Michigan, US.

EBD Journal. (2015, August 22). The knowledge problem. As architects and designers, what do we know about people? Retrieved from https://ebdjournal.com/blog/general-design/the-knowledge-problem

Grajewski, T. R. (1992). Spatial configurations and interaction patterns within office buildings. [Doctoral dissertation]. University College London (University of London), UK.

Griffiths, S. (2012). The use of space syntax in historical research: Current practice and future possibilities. Paper presented at the 8th International Space Syntax Symposium, Santiago, Chile.

Griffiths, S., \& Netto, V. M. (2015). Open Syntaxes: Towards new engagements with social sciences and humanities: Guest editorial. The Journal of Space Syntax, 6(1), i-v. 
Hillier, B., Burdett, R., Peponis, J., \& Penn, A. (1987). Creating life: Or, does architecture determine anything? Architecture \& Comportement/Architecture \& Behaviour, 3(3), 233-250.

Hillier, B., \& Grajewski, T. R. (1990). The application of space syntax to work environments inside buildings: Second phase: Towards a predictive model. In Unit for architectural studies. London: The Bartlett School of Architecture and Planning, University College London.

Hillier, B., \& Hanson, J. (1984). The social logic of space. Cambridge: Cambridge University Press.

Hillier, B., Leaman, A., Stansall, P., \& Bedford, M. (1976). Space syntax. Environment and Planning B: Planning and Design, 3(2), 147-185. https://doi.org/10.1068/b030147

Hillier, B., \& Penn, A. (1991). Visible colleges: Structure and randomness in the place of discovery. Science in Context, 4(1), 23-50. https://doi.org/10.1017/S0269889700000144

Hong, Y.-K., \& Yoo, U.-S. (2010). Workspace visibility graph analysis (VGA) for concentration privacy and group relations in the open-plan office environment. Architectural Research, 12(1), 9-14. https://doi. org/10.5659/AIKAR.2010.12.1.9

Javadi, A.-H., Emo, B., Howard, L., Zisch, F., Yu, Y., Knight, R., . . . \& Spiers, H. J. (2016). Hippocampal and prefrontal processing of network topology to simulate the future. Nature Communications, 8(1), 14652. https://doi.org/10.1038/ncomms14652

Kabo, F., Hwang, Y., Levenstein, M., \& Owen-Smith, J. (2015). Shared paths to the lab a sociospatial network analysis of collaboration. Environment and Behavior, 47(1), 57-84.

Karimi, K. (2012). A configurational approach to analytical urban design: "Space syntax" methodology. Urban Design International, 17(4), 297-318. https://doi.org/10.1057/udi.2012.19

Kegel, P. (2018). The impact of the physical work environment on organizational outcomes: A structured review of the literature. Journal of Facility Management Education and Research, 1(1), 19-29. https://doi. org/10.22361/jfmer/76637

Kishimoto, T., \& Taguchi, M. (2014). Spatial configuration of Japanese elementary schools: Analyses by the space syntax and evaluation by school teachers. Journal of Asian Architecture and Building Engineering, 13(2), 373-380.

Koutsolampros, P. (2021). Human behaviour in office environments-Finding patterns of activity and spatial configuration in large workplace datasets [Doctoral dissertation]. University College London, London, UK.

Koutsolampros, P., \& Kostourou, F. (2019). rdepthmap: R and depthmapX CLI interface (Version 0.1.0). Retrieved from https://github.com/orange-vertex/rdepthmap

Koutsolampros, P., Sailer, K., \& Haslem, R. (2020). Travel concentration: The effects of attractor bound movement on workplace activity. Paper presented at the 2nd Transdisciplinary Workplace Research Conference, Frankfurt, Germany.

Koutsolampros, P., Sailer, K., Varoudis, T., \& Haslem, R. (2019). Dissecting visibility graph analysis: The metrics and their role in understanding workplace human behaviour. Paper presented the 12 th International Space Syntax Symposium, Beijing, China.

Liebst, L. S., \& Griffiths, S. (2019). Space syntax theory and Durkheim's social morphology: A reassessment. Distinktion: Journal of Social Theory, 21(2), 1-21. https://doi.org/10.1080/1600910X.2019.1641121

Lu, Y., \& Zimring, C. (2012). Can intensive care staff see their patients? An improved visibility analysis methodology. Environment and Behavior, 44(6), 861-876. https://doi.org/10.1177/0013916511405314

Major, M., Indraganti, M., Ahmad, A., Tannous, H. O., Al-Marri, A., Alnoaimi, L., \& Al-Obaidan, M. (2019). Comfort and use in building evaluation: Information modelling and post-occupancy in the built environment. Paper presented at the 12th International Space Syntax Symposium, Beijing, China.

McElhinney, S. (2020). The Isovist_App: A basic user guide (version v1.6). Retrieved from https://isovists.org

Owen-Smith, J., Kabo, F., Levenstein, M., Price, R., \& Davis, G. (2012). A tale of two buildings: Socio-spatial significance in innovation. Ann Arbor, MI: University of Michigan.

Pachilova, R., \& Sailer, K. (2020). Providing care quality by design: A new measure to assess hospital ward layouts. The Journal of Architecture, 25(2), 186-202. https://doi.org/10.1080/13602365.2020.1733802

Penn, A., Desyllas, J., \& Vaughan, L. (1999). The space of innovation: Interaction and communication in the work environment. Environment and Planning B: Planning and Design, 26(2), 193-218. https://doi. org/10.1068/b4225

Peponis, J. (1985). The spatial culture of factories. Human Relations, 38(4), 357-390. https://doi. org/10.1177/001872678503800405

Peponis, J., Bafna, S., Bajaj, R., Bromberg, J., Congdon, C., Rashid, M., . . . \& Zimring, C. (2007). Designing space to support knowledge work. Environment and Behavior, 39(6), 815-840. https://doi. org/10.1177/0013916506297216 
Peponis, J., Bafna, S., Dahabreh, S. M., \& Dogan, F. (2015). Configurational meaning and conceptual shifts in design. The Journal of Architecture, 20(2), 215-243.

Rashid, M., Kampschroer, K., Wineman, J., \& Zimring, C. (2006). Spatial layout and face-to-face interaction in offices: A study of the mechanisms of spatial effects on face-to-face interaction. Environment and Planning B: Planning and Design, 33(6), 825-844. https://doi.org/10.1068/b31123

Sailer, K. (2007). Movement in workplace environments - Configurational or programmed? Proceedings of the 6 th international space syntax symposium. Paper presented at the 6th international space syntax symposium, Istanbul, Turkey.

Sailer, K. (2010). The space-organisation relationship: On the shape of the relationship between spatial configuration and collective organisational behaviours [Doctoral dissertation]. Germany: TU Dresden.

Sailer, K. (2015). The dynamics and diversity of space use in the British Library. ITU A $\mid Z$ Journal of the Faculty of Architecture, 12(3), 23-39.

Sailer, K., Budgen, A., Lonsdale, N., Turner, A., \& Penn, A. (2007). Effective workplaces: Bridging the gap between architectural research and design practice. Poster presented at the 6th International Space Syntax Symposium, Istanbul, Turkey.

Sailer, K., Budgen, A., Lonsdale, N., Turner, A., \& Penn, A. (2008). Evidence-based design: Theoretical and practical reflections of an emerging approach in office architecture. Paper presented the Undisciplined! Design Research Society Conference 2008, Sheffield Hallam University, Sheffield, UK.

Sailer, K., \& McCulloh, I. (2012). Social networks and spatial configuration: How office layouts drive social interaction. Social Networks, 34(1), 47-58. https://doi.org/10.1016/j.socnet.2011.05.005

Sailer, K., Pomeroy, R., \& Haslem, R. (2015). Data-driven design: Using data on human behaviour and spatial configuration to inform better workplace design. Corporate Real Estate Journal, 4(3), 249-262.

Sailer, K., Pomeroy, R., Raheem, A., Budgen, A., \& Lonsdale, N. (2012). The generative office building. Proceedings of the 8th international space syntax symposium. Paper presented at the 8th international space syntax symposium, Santiago, Chile.

Sailer, K., \& Thomas, M. (2019). Correspondence and non-correspondence: Using office accommodation to calculate an organization's propensity for new ideas. Paper presented at the 12th International Space Syntax Symposium, Beijing, China.

Sailer, K., \& Thomas, M. (2020a). From Saint Jerome's study to workplace seismographs: The role of spatial layouts in decision-making speed across different industries. Paper presented at the 2nd Transdisciplinary Workplace Research Conference, Frankfurt, Germany.

Sailer, K., \& Thomas, M. (2020b). Socio-spatial perspectives on open-plan versus cellular offices. Journal of Managerial Psychology, Forthcoming. https://doi.org/10.1108/JMP-10-2019-055

Serrato, M., \& Wineman, J. (1999). Spatial and communication patterns in research $\mathcal{E}$ development facilities. Paper presented at the 2nd International Space Syntax Symposium, Brasília, Brazil.

Steen, J., Blombergsson, M., \& Wiklander, J. (2005). Useful buildings for office activities. Facilities, 23(3/4), 176-186. https://doi.org/10.1108/02632770510578548

Thomas, M. (2019). How space affects emergent strategy: A study of the role physical space plays in the generation of social interactions in organisations [Doctoral dissertation]. Lancaster University.

Toker, U., \& Gray, D. O. (2008). Innovation spaces: Workspace planning and innovation in U.S. university research centers. Research Policy, 37(2), 309-329. https://doi.org/10.1016/j.respol.2007.09.006

Turner, A., Doxa, M., O’Sullivan, D., \& Penn, A. (2001). From isovists to visibility graphs: A methodology for the analysis of architectural space. Environment and Planning B: Planning and Design, 28(1), 103-121. https://doi.org/10.1068/b2684

Ulrich, R. S., Quan, X., Zimring, C., Joseph, A., \& Choudhary, R. (2004). The role of the physical environment in the hospital of the 21st century: A once-in-a-lifetime opportunity. Concord, CA: The Center for Health Design.

Ulrich, R. S., Zimring, C., Zhu, X., DuBose, J., Seo, H.-B., Choi, Y.-S., . . Joseph, A. (2008). A review of the research literature on evidence-based healthcare design. HERD: Health Environments Research $\mathcal{E}$ Design Journal, 1(3). https://doi.org/10.1177/193758670800100306

Varoudis, T., \& Psarra, S. (2014). Beyond two dimensions: Architecture through three dimensional visibility graph analysis. The Journal of Space Syntax, 5(1), 91-108.

Varoudis, T., Swenson, A. G., Kirkton, S. D., \& Waters, J. S. (2018). Exploring nest structures of acorn dwelling ants with X-ray microtomography and surface-based three-dimensional visibility graph analysis. Philosophical Transactions of the Royal Society B: Biological Sciences, 373(1753). https://doi.org/10.1098/ rstb.2017.0237 


\section{Kerstin Sailer and Petros Koutsolampros}

Vaughan, L. (2001). Space syntax observation manual (2001 unpublished revised ed.). London: Space Syntax Ltd. Wineman, J., \& Adhya, A. (2007). Enhancing workspace performance. Paper presented at the 6th International Space Syntax Symposium, Istanbul, Turkey.

Wineman, J., Hwang, Y., Kabo, F., Owen-Smith, J., \& Davis, G. F. (2014). Spatial layout, social structure, and innovation in organizations. Environment and Planning B: Planning and Design, 14, 1-14.

Wineman, J., Kabo, F. W., \& Davis, G. F. (2009). Spatial and social networks in organizational innovation. Environment and Behavior, 41(3), 427-442. https://doi.org/10.1177/0013916508314854

Wineman, J., \& Serrato, M. (1997). Enhancing communication in lab-based organisations. Paper presented at the 1st International Space Syntax Symposium, London, UK. 